\title{
Alleviating Effect of Exogenous Application of Ascorbic Acid on Growth and Mineral Nutrients in Cadmium Stressed Barley (Hordeum vulgare) Seedlings
}

\author{
Hira Atta Ullah ${ }^{1 *}$, Farrukh Javed ${ }^{1}$, Abdul Wahid ${ }^{1}$ and Bushra Sadia ${ }^{2}$ \\ ${ }^{1}$ Department of Botany, University of Agriculture, Faisalabad-Pakistan \\ ${ }^{2}$ Center of Agricultural Biochemistry and Biotechnology (CABB), University of Agriculture, Faisalabad, Pakistan \\ *For correspondence: hiraranauaf@gmail.com
}

\begin{abstract}
An experiment was carried out in sand-filled pots under normal temperature $\left(28 \pm 2^{\circ} \mathrm{C}\right)$ to assess the role of exogenously applied ascorbic acid in alleviating the effect of cadmium (Cd) stress on four barley (Hordeum vulgare L.) genotypes (Jau-83, Jau-87, Paidar 91 and Haider 93). After germination, seedlings were exposed to different Cd concentrations (0, 100, 300, 500 and 700 $\mu \mathrm{M} \mathrm{CdCl} 2$ ) along with AsA (200 mg L $\left.\mathrm{m}^{-1}\right)$ and grown for 15 days. The results suggested that exposure to increased Cd levels caused a significant reduction in growth and mineral nutrients contents of barley seedlings. However, there was a noticeable difference in the effect of $\mathrm{Cd}$ on mineral concentrations among genotypes and the difference mainly coincided with differential accumulation of $\mathrm{Cd}$ in the shoot and root tissues. When AsA was applied to Cd-stressed plants, it decreased Cd accumulation in shoots and roots and also showed partial reversal of $\mathrm{Cd}$ stress effects. It was also observed that at the same Cd concentrations Cd tolerance index of Jau- 83 was the highest among the four barley genotypes, indicating that Jau- 83 had lower Cd contents in roots may be more tolerant to Cd stress. The application of AsA was effective in reducing the toxicity of increased Cd by reducing the root or shoots $\mathrm{Cd}$ contents, as well as by improving the seedling growth attributes and the mineral nutrients in barley. () 2016 Friends Science Publishers
\end{abstract}

Keywords: Barley; Cadmium; Growth; Mineral nutrition

\section{Introduction}

Cadmium (Cd) is highly toxic, non-essential environmental pollutant found in air, water and soil (Sandalio et al., 2001; Benavides et al., 2005). One of the major sources of addition of $\mathrm{Cd}$ into agricultural soils is the application of phosphate fertilizers (Grant and Sheppard, 2008). The other sources for increasing $\mathrm{Cd}$ pollution in the soil are industrial effluents such as manufacture of plastics, paint pigments, batteries, alloy making, electroplating and manures (Devkota and Schmidt, 2000; Nedelkoska and Doran, 2000; Yang et al., 2004).

Cadmium can be taken up by the plants along with water and nutrients, when cultivated in Cd-polluted soil (Sheppard et al., 2007). Although Cd has been identified as a reason for various morphological, physiological, biochemical and structural alterations in plants, water disproportion and decreasing in rate of seed germination are the specific mechanisms in this regard (Mishra et al., 2006; Wahid and Khaliq, 2015). Moreover, Cd causes various phytotoxic symptoms such as browning of root tips, reduction in root length, thus resultantly directed to diminish development and less biomass accretion and finally plant death (Sanita di
Toppi and Gabbrielli, 1999; Wahid et al., 2008).

A noticeable effect of $\mathrm{Cd}$ addition in growth medium is a marked reduction in shoot length of wheat (Veselov et al., 2003), Phaseolus vulgaris (Bhardwaj et al., 2009) and barley (Gubrelay et al., 2013). Similarly, Cd inhibits root growth more promptly than shoot growth (Vitoria et al., 2001). Hence, $\mathrm{Cd}$ addition reduced the shoot fresh and dry weight also have been studied previously in different plant species such as wheat (Mane et al., 2010) and barley (Zaltauskaite and Sliumpaite, 2013). Cadmium may impede with nutrient uptake due to competition for the same transmembrane carriers, thereby leading to the altered tissue nutrient contents (Connolly et al., 2002). These interactions between $\mathrm{Cd}$ and other essential nutrients may lead to physiological disarrays as well as a reduction in growth (ElBeltagi et al., 2010). Cadmium exposure significantly affected essential ions in roots and shoots has been explored in rice (Liu et al., 2003), wheat (Zhang et al., 2002), barley (Wu and Zhang, 2002) and lettuce (Monteiro et al., 2009). These mineral nutrients also have specific of defensive role against lethal effects of Cd (Khan et al., 2007).

To cite this paper: Atta Ullah, H., F. Javed, A. Wahid and B. Sadia, 2016. Alleviating effect of exogenous application of ascorbic acid on growth and mineral nutrients in cadmium stressed barley (Hordeum vulgare) seedlings. Int. J. Agric. Biol., 18: 73-79 
Ascorbic acid (AsA) is a strong antioxidant and abundantly occurs in plants (Smirnoff, 2000). It plays many important roles in various cellular processes. It is involved in cell division and cell wall expansion, and regulates the plant growth and development (Pignococchi and Foyer, 2003). Exogenous application of AsA stimulates total leaf area, photosynthetic pigments and growth of plants under drought stress (Amin et al., 2009). AsA is one of the most effective compounds, which improve the tolerance of the plants to oxidative stresses. A wealth of information suggests that AsA plays significant role in protection of plant against several environmental circumstances (Paital and Chainy, 2010), such as salt stress (Shalata and Neumann, 2001), ozone (Sanmartin et al., 2003), UV-B and pathogenesis (Fotopoulos et al., 2006), drought (Fotopoulos et al., 2008), and in heavy metal stress (Vwioko et al., 2008).

Barley is ranked fourth-largest cereal crop, rich in carbohydrate along with moderate amount of protein, phosphorus, calcium and minor amount of vitamin B (Daniel and Hopf, 2000). It is constituent of many foods. Barley is commonly used for beer production. In Pakistan, barley is extensively used as green fodder for livestock feed and for small ruminant animals in winter (Khan et al., 1999). We hypothesize that Cd-toxicity to barley can be alleviated by exogenous AsA application due to its antioxidative role. The objective of the present study was to assess the role of ascorbic acid in the alleviation of toxic effects on seedling growth parameters, mineral nutrients and the genotypic responses to $\mathrm{Cd}$ toxicity.

\section{Materials and Methods}

\section{Experimental Details}

The pot experiment was conducted in the growth chamber under controlled conditions of light and temperature $\left(28 \pm 2^{\circ} \mathrm{C}\right)$ in the Dept. of Botany, University of Agriculture, Faisalabad, Pakistan. Seeds of barley genotypes (Jau-83, Jau87, Paidar 91 and Haider 93) were obtained from Ayub Agricultural Research Institute, Faisalabad. Cadmium levels were prepared using cadmium chloride $\left(\mathrm{CdCl}_{2}\right)$. Ten seeds of each genotype were sown in small plastic pots containing washed river sand under five cadmium treatments $(0,100$, 300,500 and $700 \mu \mathrm{M}$ ) and $200 \mathrm{mg} \mathrm{L}^{-1}$ of AsA. Treatment combinations used during the course of study were: $0 \mu \mathrm{M} \mathrm{Cd}$ $+0 \mathrm{mg}$ AsA, 100, 300, 500 and $700 \mu \mathrm{M} \mathrm{Cd}$ with or without the application of AsA. After germination, the seedlings were irrigated at alternate day intervals with half strength of Hoagland's solution (Hoagland and Arnon, 1950) along with the corresponding $\mathrm{Cd}$ treatment combination for 15 days. After harvesting the plants, different seedling growth parameters and contents of mineral nutrients were measured.

\section{Growth Determination}

Shoot and root lengths and their fresh weights were measured immediately after harvesting. For taking their dry weights, both the parts were put in paper bags and dried in an oven for 7 days.

\section{Determination of Mineral Nutrients}

The dried ground material $(0.5 \mathrm{~g})$ of shoots, and roots were digested in concentrated $\mathrm{HNO}_{3}(5 \mathrm{~mL})$ at $100^{\circ} \mathrm{C}$ temperature and then raised the temperature gradually to $250^{\circ} \mathrm{C}$ until the samples became clear. Then made volume of the extracted up to $50 \mathrm{~mL}$ using a volumetric flask. Filtered the extract and used it for the determination of mineral nutrients concentrations. The dissolved amount of potassium $(\mathrm{K})$ and calcium $(\mathrm{Ca})$ were determined by using flame photometer (Model: PFPI-7, Jenway, UK), while magnesium (Mg) and cadmium $(\mathrm{Cd})$ were determined with atomic absorption spectrometer (Model: AAnalyst-3100 Perklin Elmer, USA). Cd content was calculated by multiplying the dry weight of root or shoot with their $\mathrm{Cd}$ concentration.

The phosphorus $(\mathrm{P})$ content was determined according to (Yoshida et al., 1972). One gram of dried and ground plant tissue was digested with $10 \mathrm{~mL}$ of acid mixture (nitric acid, $750 \mathrm{~mL}$; sulphuric acid, $150 \mathrm{~mL}$; perchloric acid 60 per cent, $300 \mathrm{~mL}$ ). The digest was cooled and made up to $50 \mathrm{~mL}$ and filtered through acid washed Whatmann No.1 filter paper. One $\mathrm{mL}$ of digest was mixed with $2 \mathrm{~mL}$ of $2 \mathrm{~N}$ nitric acid and diluted to $8 \mathrm{~mL}$. One $\mathrm{mL}$ of molybdovanadate reagent $(25 \mathrm{~g}$ of ammonium molybdate in $500 \mathrm{~mL}$ water, $1.25 \mathrm{~g}$ ammonium vanadate in $500 \mathrm{~mL}$ of $1 \mathrm{~N}$ nitric acid; both were mixed in equal volumes) was added, make up to $10 \mathrm{~mL}$, shacked and the absorbance was measured at $420 \mathrm{~nm}$ in a spectrophotometer.

\section{Statistical Analysis}

Design of the experiment was completely randomized factorial with three replications per treatment. Analysis of variance of data for all parameter was carried out to find out the significance of variance sources and Duncan's New Multiple Range test $(P \leq 0.05)$ was used to find differences among the treatments by using a computer software COSTAT (Cohort software Berkeley, California).

\section{Results}

\section{Growth Parameters}

The data for different growth parameters indicated significant $(\mathrm{P}<0.05)$ differences amongst the barley varieties as well as amongst different treatments. The growth data indicated that addition of $\mathrm{Cd}$ to the nutrient medium caused a visually noticeable reduction in growth parameters. At low concentration of $\mathrm{Cd}(100 \mu \mathrm{M})$, minor effect was noticed, while at high concentration of cadmium $700 \mu \mathrm{M}$ very strong inhibitory effects were observed in among genotypes. The extent of reduction was more pronounced in root length as compared to shoot length (Fig. 1). Cd-induced growth 

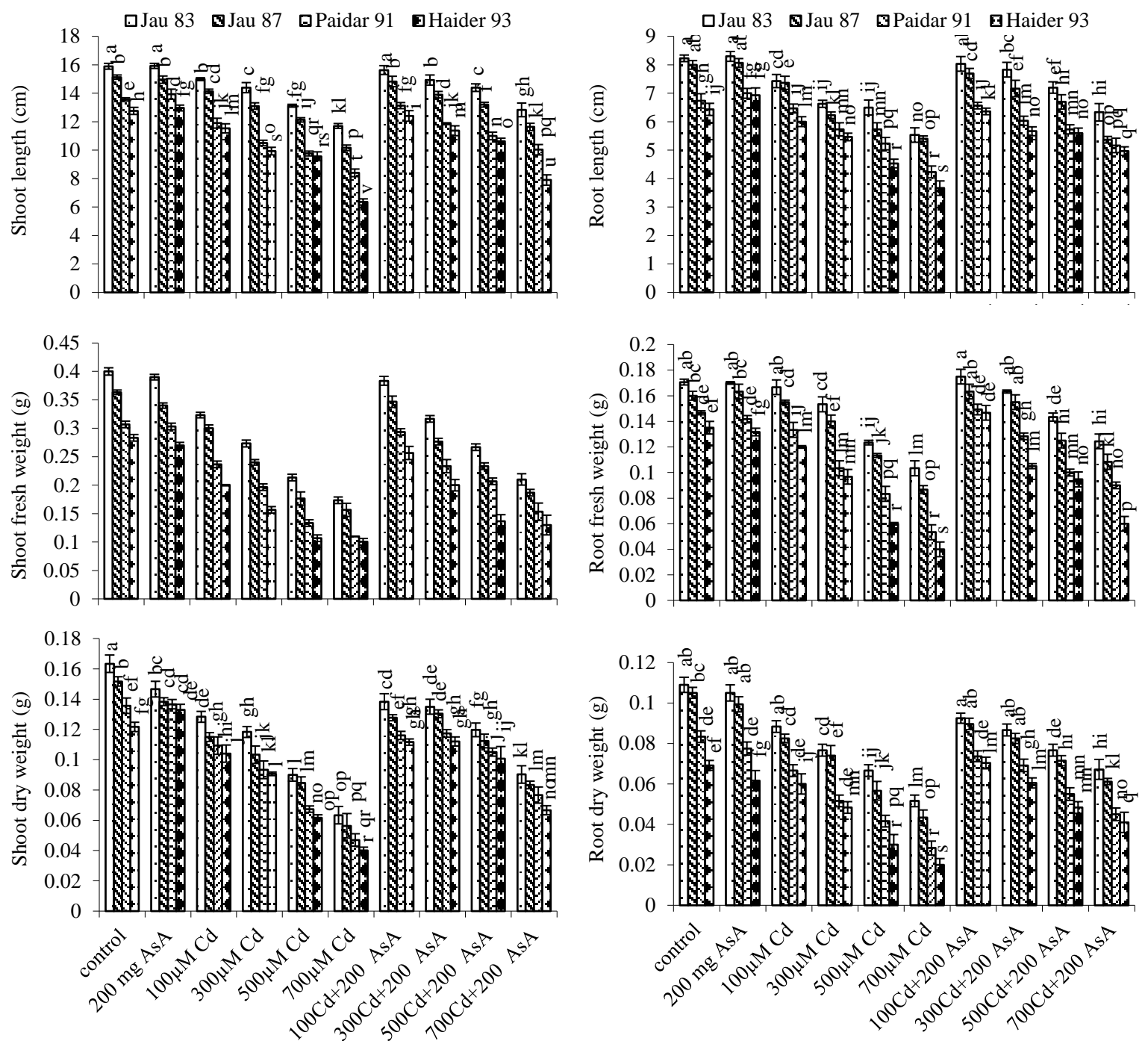

Fig. 1: Main effects of cadmium (Cd), ascorbic acid (AsA) and their interactions on shoot and root growth of four barley genotypes

diminishing tendency was in the order: root length, shoot length, and shoot fresh and dry weight (Fig. 1). Among the genotypes Jau-83 indicated better tolerance to cadmium toxicity and more improvement was recorded with the medium supplementation of AsA in the order: Jau- $83<$ Jau$87<$ Paidar $91<$ and Haider 93 .

\section{Mineral Nutrients}

Changes observed with increased levels $\mathrm{Cd}$ on the shoot and root $\mathrm{K}^{+}, \mathrm{Ca}^{2+}, \mathrm{P}$ and $\mathrm{Mg}^{2+}$ contents. The data indicated significant $(\mathrm{P}<0.01)$ differences in $\mathrm{Cd}$ and $\mathrm{AsA}$ treatments and genotypes for the accumulation of the mineral ions. Medium applied Cd levels declined the tissue concentrations of all the nutrients measured in four barley genotypes, compared to control.
In the present study, $\mathrm{Cd}$ addition decreased shoots and root $\mathrm{K}^{+}$contents of all the four barley genotypes (Fig. 2). The decrease in $\mathrm{K}^{+}$contents was higher at $\mathrm{Cd}$ level $700 \mu \mathrm{M}$ in comparison to $100 \mu \mathrm{M}, 300 \mu \mathrm{M}$ and $500 \mu \mathrm{M}$ Cd levels. The rate of decrease in $\mathrm{K}^{+}$contents was higher in Haider 93 followed by Paidar 91, Jau-87 and a least decline was observed in Jau-83 (Fig. 2). $\mathrm{Ca}^{2+}$ content of Cd treated barley seedlings decreased as $\mathrm{Cd}$ level increased in the growth medium. A minor decrease in $\mathrm{Ca}^{2+}$ contents was seen at $\mathrm{Cd}$ level $100 \mu \mathrm{M}$, while this reduction increased with the increase in $\mathrm{Cd}$ level. At $700 \mu \mathrm{M} \mathrm{Cd}$ level, maximum reduction was observed in all barley genotypes. Jau- 83 was generally higher in $\mathrm{Ca}^{2+}$ contents of shoot and root than in Jau-87, Paider 91 and Haider 93 under both control and $\mathrm{Cd}$ stress conditions (Fig. 2).

Cadmium application in present study greatly affected 
Att Ullah / Int. J. Agric. Biol., Vol. 18, No. 1, 2016
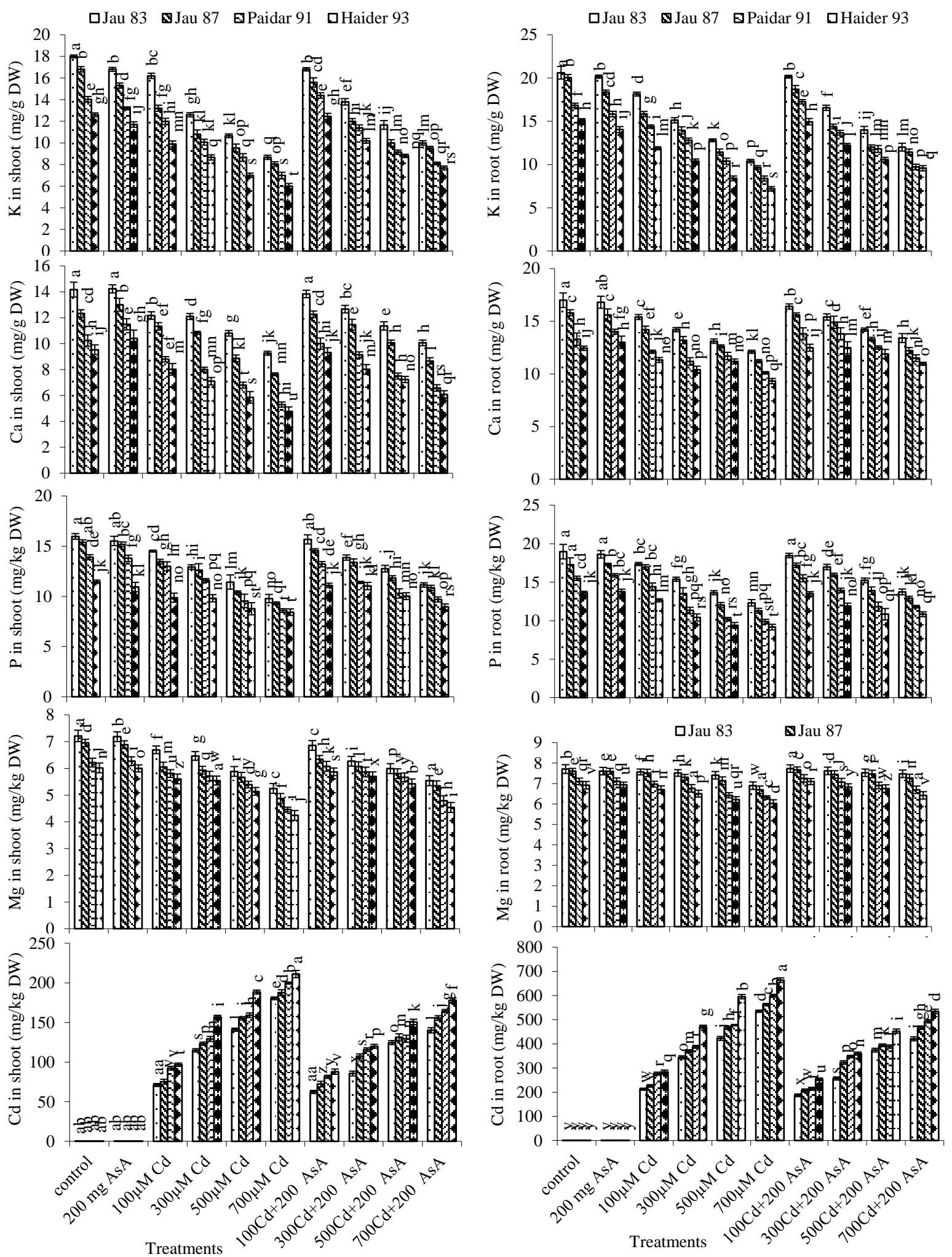

Fig. 1: Main effects of cadmium (Cd), ascorbic acid (AsA) and their interactions on shoot and root nutrinet and $\mathrm{Cd}$ contents in barley gentypes 
$\mathrm{P}$ contents in both shoot and root of all the barley genotypes compared to control. This reduction was in a Cdconcentration dependent manner. At $100 \mu \mathrm{M} \mathrm{Cd}$, a slight reduction in $\mathrm{P}$ contents was noticed, while this reduction was more pronounced as the $\mathrm{Cd}$ level increased and at 700 $\mu \mathrm{M}$ P content was affected the most. Decrease in tissue $\mathrm{P}$ order of genotypes was; Jau- $83<$ Jau- $87<$ Paidar$91<$ Haider-93 (Fig. 2).

Increasing $\mathrm{Cd}$ levels also led to the continuous decrease in $\mathrm{Mg}^{2+}$ contents both shoot and root in all the four barley genotypes. $\mathrm{Mg}^{2+}$ contents exhibited the corresponding reduction at lower level $100 \mu \mathrm{M}$ of Cd stress compared to control, while this reduction increased at 300 and $500 \mu \mathrm{M}$ Cd level but was the highest at $700 \mu \mathrm{M}$. The order of genotypes for changes in $\mathrm{Mg}^{2+}$ accumulation was: Jau-83 $<$ Jau-87 $<$ Paidar $91<$ Haider 93 . On the other hand AsA used in the current exploration substantially enhancing $\mathrm{Mg}^{2+}$ in all the barley genotypes (Fig. 2).

\section{Cadmium Contents}

All the treatments and genotypes differed significantly $(\mathrm{P}<0.01)$ for the accumulation of $\mathrm{Cd}$ in shoot and root. As predicted, $\mathrm{Cd}$ contents were consistently higher in roots compared to shoots with increased in cadmium concentration. Similarly, Cd contents increased in all the genotypes with the increasing $\mathrm{Cd}$ concentration, maximum accumulation was detected at $700 \mu \mathrm{M}$ Cd level showed in (Fig. 2). Among the genotypes, Haider 93 accumulated the highest $\mathrm{Cd}$ followed by Paidar 91, Jau-87 but it was the least in Jau-83 (Fig. 2). Addition of AsA in the growth medium reduced the accumulation of $\mathrm{Cd}$ contents in all genotypes. Jau-83 showed more tolerance against $\mathrm{Cd}$ toxicity with or without ascorbic acid application and accumulated less Cd contents.

\section{Discussion}

Adverse effects produced by $\mathrm{Cd}$ toxicity diminished the growth of the seedlings, as evident from different growth parameters interpreted above. The effect of increased $\mathrm{Cd}$ concentrations on these growth parameters revealed that low levels of $\mathrm{Cd}$ had small effect on growth parameters, while higher levels were strongly damaging. Among $\mathrm{Cd}$ concentrations, the most damaging was $700 \mu \mathrm{M}$ (Fig. 1). Amongst different growth parameters, the most deteriorating effects due to excessive $\mathrm{Cd}$ were noticed on the root elongation, which was expected because the roots are in direct contact with $\mathrm{Cd}$ from the soil solution. A decline in growth might be due to impeded normal physiological functions and replacement of essential mineral nutrients by the $\mathrm{Cd}$. In the current study, external supply of AsA appreciably enhanced growth parameters (shoot, root lengths, shoot, and root fresh and dry weights). Being a growth promoter, AsA positively influences the mineral uptake and diminishes the adverse effect of abiotic stresses (Wu and Zhang, 2002; Sheteawi, 2007; Athar et al., 2008).

Studies show that, among other effects, $\mathrm{Cd}$ induces deficiency and imbalance of mineral nutrients in different plant species (Eun et al., 2000; Wahid et al., 2008; Mane et al., 2010), while the toxicity of Cd can be diminished with the use of growth promoters (Raza et al., 2013; Fatima et al., 2014; Perveen et al., 2015). Ideal plant development can be attained with the optimal physiological levels of essential nutrients. Deficiency of even a single nutrient may lead to death of plant (Taiz and Zeiger, 2015). In the present case, $\mathrm{Cd}$ stress considerably reduced the mineral nutrients $(\mathrm{Ca}, \mathrm{K}, \mathrm{P}$ and $\mathrm{Mg}$ ) contents in shoots and roots in all the barley genotypes, this reduction was more pronounced in Haider 93 as compared to other genotypes, and root tissue was more adversely affected (Fig. 2). It has been argued that $\mathrm{Cd}$ impinges negative impact on the uptake of beneficial nutrient since it competes with them at plasma lemma level (Wahid et al., 2009; Asgher et al., 2015).

It is important to mention that AsA application enhanced the uptake of mineral nutrients in this study by reducing the tissue contents of $\mathrm{Cd}$ and thereby reducing its toxicity more on the shoot than on the root of all barley genotypes. In such instances, the prolific root system and retention of Cd by AsA may defend the shoots as a strategy of evasion from Cd toxicity (Chaoui et al., 1997). Ascorbic acid application in combination with elevating $\mathrm{Cd}$ stress caused decline in root $\mathrm{Cd}$ accumulations, and thus encountered the $\mathrm{Cd}$ toxicity (Wu and Zhang, 2002). Hussein et al. (2011) reported that AsA being antioxidant and potential growth regulator usually stimulates the mineral uptake in many plant species and diminished the harmful effect of abiotic stresses. Different genotypes differed greatly in their behavior toward $\mathrm{Cd}$ uptake and tolerance, which provided room for future research in the field of $\mathrm{Cd}$ tolerance using exogenous application of AsA.

\section{Conclusion}

Although with large varietal difference, $\mathrm{Cd}$ toxicity adversely affected the growth and nutrients uptake whilst the AsA application, due to its antioxidant properties, partially reduced the $\mathrm{Cd}$ toxicity on barley. The genotypes Jau-83 emerged as most tolerant $\mathrm{Cd}$ because growth and mineral nutrients were less affected as compared to other genotypes. Further studies are needed to find the possible mechanism(s) of the growth improvement in barley and possibly other crop species.

\section{Acknowledgements}

The first author acknowledges the financial grant from Higher Education Commission of Pakistan for Ph.D. indigenous fellowship program. 


\section{References}

Amin, B., G. Mahleghah, H.M.R. Mahmood and M. Hossein, 2009. Evaluation of interaction effect of drought stress with ascorbate and salicylic acid on some of physiological and biochemical parameters in okra (Hibiscus esculentus L.). Res. J. Biol. Sci., 4: 380-387

Asgher, M., M.I.R. Khan, N.A. Anjum and N.A. Khan, 2015. Minimising toxicity of cadmium in plant - role of plant growth regulators. Protoplasma, 252: 399-413

Athar, H.R., A. Khan and M. Ashraf, 2008. Exogenously applied ascorbic acid alleviates salt induced oxidative stress in wheat. Environ. Exp. Bot., 63: 224-231

Benavides, M.P., S.M. Gallego and M.L. Tomaro, 2005. Cadmium toxicity in plants. Braz. J. Plant Physiol., 17: 21-34

Bhardwaj, P., A.K. Chaturvedi and P. Prasad, 2009. Effect of enhanced lead and cadmium in soil on physiological and biochemical attributes of Phaseolus vulgaris L. Nat. Sci., 7: 8

Chaoui, A., S. Mazhoudi, E. Ghorbal and E. El Ferjani, 1997. Cadmium and zinc induction of lipid peroxidation and effects on antioxidant enzyme activities in bean (Phaseolus vulgaris L.). Plant Sci., 127: 139-147

Connolly, E.L., J.P. Fett and M.L. Guerinot, 2002. Expression of the IRT1 metal transporter is controlled by metals at the levels of transcript and protein accumulation. Plant Cell, 14: 1347-1357

Daniel, Z. and M. Hopf, 2000. Domestication of Plants in the Old World: The Origin and Spread of Cultivated Plants in West Asia, Europe, and the Nile Valley $3^{\text {rd }}$ edition, pp: 59-69. Oxford University Press, UK

Devkota, B. and G.H. Schmidt, 2000. Accumulation of heavy metals in food plants and grasshoppers from the Taigetos Mountains, Greece. Agric. Ecosyst. Environ., 78: 85-91

El-Beltagi, H.S., A.A. Mohamed and M.M. Rashed, 2010. Response of antioxidative enzymes to cadmium stress in leaves and roots of radish (Raphanus sativus L.). Notulae Sci. Biol., 2: 76-82

Eun, S.O., H.S. Youn and Y. Lee, 2000. Lead disturbs microtubule organization in the root meristem of Zea mays. Physiol. Plant., 110: 357-365

Fatima, R.N., F. Javed and A. Wahid, 2014. Salicylic acid modifies growth performance and nutrient status of rice (Oryza sativa) under cadmium stress. Int. J. Agric. Biol., 16: 1083-1090

Fotopoulos, V., D. Tullio, J. Barnes and A.K. Kanellis, 2008. Altered stomatal dynamics in ascorbate oxidase over-expressing tobacco plants suggest a role for dehydroascorbate signaling. J. Exp. Bot., 59: 729-737

Fotopoulos, V., M. Sanmartin and A.K. Kanellis, 2006. Effect of ascorbate oxidase overexpression on ascorbate recycling gene expression in response to agents imposing oxidative stress. J. Exp. Bot., 57: 39333943

Grant, C.A. and S.C. Sheppard, 2008. Fertilizer impacts on cadmium availability in agricultural soils and crops. Hum. Ecol. Risk Assess., 14: $210-228$

Gubrelay, U., K. Rajneesh, A.G. Singh, R. Kaur1 and R. Sharma, 2013. Effect of heavy metal $\mathrm{Cd}$ on some physiological and biochemical parameters of Barley (Hordeum vulgare L.). Int. J. Agric. Crop Sci., 5: 2743-2751

Hoagland, D.R. and D.I. Arnon, 1950. The Water Culture Method for Growing Plants without Soil. Uni. Calif., Berkeley College Agric. Exp. Stn. Circ., No. 347

Hussein, M.M., K.M. Abd El-Rheem, S.M. Khaled and R.A. Youssef, 2011. Growth and nutrients status of wheat as affected by ascorbic acid and water salinity. Nat. Sci., 9: 64-69

Khan, M.A., S. Ahmad, I. Begum, A.S. Alvi and M.S. Mughal, 1999. Development of barley as a feed/fodder crop for the Mediterranean environment of highland Balochistan, Pakistan. Cah. Opt. Mediterranean, 39: 229-233

Khan, N.A. Samiullah, S. Singh and R. Nazar, 2007. Activities of antioxidative enzymes, sulphur assimilation, Photosynthetic activity and growth of wheat (Triticum aestivum) cultivars differing in yield potential under cadmium stress. J. Agron. Crop. Sci., 193: 435-444

Liu, J., K. Li, J. Xu, J. Liang, X. Lu, J. Yang and Q. Zhu, 2003. Interaction of $\mathrm{Cd}$ and five mineral nutrients for uptake and accumulation in different rice cultivars and genotypes. Field Crops Res., 83: 271-281
Mane, A.V., R.R. Sankpal, L.A. Mane and M.S. Ambawade, 2010. Cadmium chloride induced alteration in growth and cadmium accumulation in Triticum aestivum (1.) var. MP LOK 1. J. Chem. Pharm. Res., 2: 206215

Mishra, S., S. Srivastava, R.D. Tripathi, R. Kumar, C.S. Seth and D.K Gupta, 2006. Lead detoxification by coontail (Ceratophyllum demersum L.) involves induction of phytochelatins and antioxidant system in response to its accumulation. Chemosphere, 65: 1027-1039

Monteiro, M.S., C. Santos, V.M. Soares and R.M. Mann, 2009. Assessment of biomarkers of cadmium stress in lettuce. Ecotoxicol. Environ. Saf., 72: $811-818$

Nedelkoska, T.V. and P.M. Doran, 2000. Characteristics of heavy metal uptake by plants species with potential for phytoremediation and phytomining. Minerals Eng., 13: 549-561

Paital, B. and G.B.N. Chainy, 2010. Antioxidant defenses and oxidative stress parameters in tissues of mud crab (Scylla serrata) with reference to change salinity. Original Research Article. Comparative Biochemistry and Physiology, Part C: Toxicol. Pharmacol., 151: 142-147

Perveen, A., A. Wahid, S. Mahmood, I. Hussain and R. Rasheed, 2015. Possible mechanism of root-applied thiourea in improving growth, gas exchange and photosynthetic pigments in cadmium stressed maize (Zea mays). Braz. J. Bot., 38: 71-79

Pignococchi, C. and C.H. Foyer, 2003. Apoplastic ascorbate metabolism and its role in the regulation of cell signalling. Curr. Opin. Plant Biol., 6: 379-89

Raza, S.H. and F. Shafiq, 2013. Exploring the role of salicylic acid to attenuate cadmium accumulation in radish (Raphanus sativus). Int. $J$. Agric. Biol., 15: 547-552

Sandalio, L.M., H.C. Dalurzo, M. Gomez, M.C. Romero-Puertas and L.A.D Rio, 2001. Cadmium-induced changes in the growth and oxidative metabolism of pea plants. J. Exp. Bot., 52: 2115-2126

Sanita di Toppi, L. and R. Gabbrielli, 1999. Response to cadmium in higher plants. Environ. Exp. Bot., 41: 105-130

Sanmartin, M., P.D. Drogoudi, T. Lyons, I. Pateraki, J. Barnes and A.K. Kanellis, 2003. Overexpression of ascorbate oxidase in the apoplast of transgenic tobacco results in altered ascorbate and glutathione redox states and increased sensitivity to ozone. Planta, 216: 918-928

Shalata, A. and P.M. Neumann, 2001. Exogenous ascorbic acid (vitamin C) increases resistance of salt stress and reduces lipid peroxidation. $J$. Exp. Bot., 52: 2207-2211

Sheppard, M.I., S.C. Sheppard and C.A. Grant, 2007. Solid/liquid partition coefficients to model trace element critical loads for agricultural soils in Canada. Can. J. Soil Sci., 87: 189-201

Sheteawi, S.A., 2007. Improving growth and yield of salt-stressed soybean by exogenous application of ascobin. Int. J. Agric. Biol., 9: 473-478

Smirnoff, N., 2000. Ascorbic acid: metabolism and functions of a multifacetted molecule. Curr. Opin. Plant Biol., 3: 229-235

Taiz, L. and E. Zeiger, 2015. Plant Physiology, $6^{\text {th }}$ edition. Sinauer Associates Inc. Publishers, Sunderland, Massachusetts, USA

Veselov, D., G. Kudoyarova, M. Symonyan and S. Veselov, 2003. Bulg. J. Plant Physiol., Special issue, 353-359

Vitoria, A.P., P.J. Lea and R.A. Azevedo, 2001. Antioxidant enzymes responses to cadmium in radish tissues. Phytochemistry, 57: 701-710

Vwioko, E.D., M.E. Osawaru and O.L. Eruogun, 2008. Evaluation of okra (Abelmoschus esculentus L. Moench.) exposed to paint waste contaminated soil for growth, ascorbic acid and metal concentration. Afr. J. Gen. Agric., 4: 39-48

Wahid, A. and S. Khaliq, 2015. Architectural and biochemical changes in embryonic tissues of maize under cadmium toxicity. Plant Biol., 17: 1005-1012

Wahid, A., A. Ghani and F. Javed, 2008. Effect of cadmium on photosynthesis, nutrition and growth of mungbean. Agron. Sustain. Dev., 28: 273-280

Wahid, A., M. Arshad and M. Farooq, 2009. Cadmium phtotoxicity: response, mechanisms and mitigation strategies. In: Advances in Sustainable Agriculture, Vol. 1, pp: 371-403. Lichtfouse, E. (ed.). Springer, Dordrecht, the Netherland

Wu, F. and G. Zhang, 2002. Alleviation of cadmium toxicity by the application of zinc and ascorbic acid in barley. J. Plant Nutr., 25: 2745-2761 
Exogenously Applied Ascorbic Acid Alleviates Cadmium Toxicity in Barley / Int. J. Agric. Biol., Vol. 18, No. 1, 2016

Yang, X.E., X.X. Long, H.B. Ye, Z.L. He, D.V. Calvert and P.J. Stofella, 2004 Cadmium tolerance and hyperaccumulation in a new $\mathrm{Zn}$ hyperaccumulating plant species (Sedum alfredii Hance). Plant Soil, 259: $181-189$

Yoshida, S., D.A. Forno, J. Cock and K.A, Gomez, 1972. Laboratory Manual for Physiological Studies of Rice. IRRI, Los Banos, Philippines
Zaltauskaite, J. and I. Sliumpaite, 2013. Evaluation of toxic effects and bioaccumulation of cadmium and copper in spring barley (Hordeum vulgare). Environ. Res. Eng. Manage., 2: 51-58

Zhang, G.P., M. Fukami and H. Sekimoto, 2002. Influence of cadmium on mineral concentrations and yield components in wheat genotypes differing in Cd tolerance at seedling stage. Field Crops Res., 77: 93-98

(Received 23 May 2015; Accepted 06 July 2015) 